\title{
Soil Microarthropods in a Secondary Rainforest, Rivers State, Nigeria - IV- The Impact of Oil Pollution on Their Vertical Distribution
}

\author{
Samuel N. Okiwelu ${ }^{1,3, *}$, Tambeke N. Gbarakoro ${ }^{1}$, Chris O. Umeozor ${ }^{1}$, Adetola M Badejo ${ }^{2}$ \\ ${ }^{1}$ Department of Animal and Environmental Biology, University of Port Harcourt, Port Harcourt, Nigeria \\ ${ }^{2}$ Department of Zoology, Obafemi Awolowo University, Ile-Ife, Nigeria
}

\begin{abstract}
Studies were undertaken, May, 2007-April, 2009, to document species richness, bioindicator species, abundance, density, vertical distribution, etc. of soil microarthropods (mites, collembolans) in unpolluted and polluted habitats in a secondary rainforest, Rivers State, Nigeria. This paper focuses on the effects of oil pollution on the vertical distribution of these mesofauna. Sampling was effected monthly by a bucket-type auger to a depth of $15.0 \mathrm{~cm}$ in four habitat-types (unpolluted, polluted by oil spills approximately 1yr, 3yrs and 6yrs pre-study). The modified Bukard model of the Berlese-Tullgren funnel was used for extraction. Identifications were undertaken using standard keys and unidentified specimens were compared to type specimens. In the unpolluted and polluted ( 3 and 6yrs pre-study) habitats, there was an inverse relationship between mite/ collembolan abundance/density (except in the Prostigmata) and soil depth; however, the correlations were not significant. In contrast, there was a significant direct correlation between mite abundance/density and depth in the habitat, polluted $1 \mathrm{yr}$ pre-study $(\mathrm{F}=29.11 ; \mathrm{df}=1.3 ; \mathrm{p}<0.05)$. In the unpolluted habitat, approximately $80 \%$ of all mites and $90 \%$ of collembolans were collected within the range $0.00-10.0 \mathrm{~cm}$. In the habitat, polluted 1yr pre-study, no mites were collected above a depth of $5.0 \mathrm{~cm}$ and $70 \%$ were found below $10.0 \mathrm{~cm}$. In the habitats, polluted 3 and $6 y$ rs pre-study, approximately all mites were found above a depth of $10.0 \mathrm{~cm}$. There were direct relationships between collembolan densities and soil depths in the two habitat-types (polluted 1 and 3 yrs pre-study) but the correlations were not significant $(\mathrm{F}=6.22$; $\mathrm{df}=1.3 ; \mathrm{p}>0.05)$. In the unpolluted habitat, approximately $90 \%$ of all collembolans were found above a depth of $10.0 \mathrm{~cm}$; this declined to $30 \%$ in the habitat, polluted 1yr pre-study, and rose to $50 \%$ and $85 \%$ in the habitats, polluted 3 and $6 y$ rs pre-study.
\end{abstract}

Keywords Soil Microarthropods, Oil Pollution, Effects, Vertical Distribution

\section{Introduction}

Globally, investigations have been conducted on the responses of soil microarthropods (mites and collembolans) to various stressors: site preparation techniques[1] heavy metals[2-5], organic carbon content[6-8] organic manure[9], inorganic fertilizer[10], ash treatment of sour, acidic coils[11], herbicides and pesticides[12,6]. The effects of petroleum spill on these microarthropods have received limited attention. Studies on the soil microarthropods of tropical Africa have been minimal, compared to those in the palaeartic and neartic regions. Fortunately,[13-16] have made significant progress in the taxonomy and ecology of soil microarthropods in Nigeria. However, their studies were restricted to a depth of $7.50 \mathrm{~cm}$ in southwest Nigeria. Some of

* Corresponding author:

okiwelu2003@yahoo.com (Samuel N. OKIWELU)

Published online at http://journal.sapub.org/ re

Copyright (C) 2012 Scientific \& Academic Publishing. All Rights Reserved the results from the current studies have been documented $[17,18]$; this report focuses on the vertical distribution of soil microarthropods in 4 habitat-types (unpolluted, polluted by an oil spill; 1yr, 3yrs and 6yrs pre-study) in a secondary forest, Rivers State, Nigeria.

\section{Materials and Methods}

\subsection{Study Area}

The habitat-types were located in a secondary lowland rainforest in Tai Local Government Area, Rivers State, Nigeria. Two of the habitats (unpolluted and polluted 3yrs pre-study), $04^{\circ} 44.16 \mathrm{~N}, 007^{\circ} 12.32^{\prime} \mathrm{E}$ and $04^{\circ} 44.14 \mathrm{~N}, 007^{\circ} 29^{\prime}$ respectively, were at Norkpo; the habitats polluted $1 \mathrm{yr}$ and $6 y$ rs pre-study were sited at Kporgior and Gio respectively (Figure 1).

\subsection{Methods}

A $3500 \mathrm{~m}^{2}$ - area was demarcated within each habitat; it 
was subsequently divided into twelve $24 \times 12 \mathrm{~m}$ sub-plots to ensure total coverage during monthly sampling over a 2-year period, May, 2007-April, 2009. Soil samples were taken monthly with an $8.5 \mathrm{~cm}$-diameter bucket- type auger at the southern section of each sub-plot during the first year, May 2007-April 2008. In the second year, May 2008-May 2009, samples were taken from the northern section. Depths of soil collections were: $0-5.0 \mathrm{~cm}, 5.1-7.5 \mathrm{~cm}, 7.6-10.0 \mathrm{~cm}$. $10.1-12.5 \mathrm{~cm}$ 1nd $12.6-15.0 \mathrm{~cm}$. To ensure that all the soil in each range was collected, the auger was rotated clockwise and anti-clockwise, until the entire soil was taken.

Each sample was placed in a plastic bag, labelled and taken to the laboratory for analyses, by a 3-stage process (extraction, sorting, and identification). The modified Bukard model of the Berlese-Tullgren funnel was used for extraction[19]. The extractor complex consisted of two 8-unit rows, enclosed in a wooden cabinet. Description of the extractor complex and extraction procedure has been documented[20]. The duration of extraction was 7 days. The extracts containing soil microarthropods were placed in Petri-dishes under a dissecting microscope; the mites and collembolans were carefully removed. Temporary slides were prepared and identification undertaken under a compound microscope at the Entomology Research Laboratory, Department of Animal and Environmental Biology, University of Port Harcourt. Identification keys by[21-23] were used. Unidentified specimens were taken to the Laboratory of Systematics and Ecology of Microarthropods, Department of Zoology, Obafemi Awolowo University, Ile-Ife, Nigeria, where they were compared to type specimens.

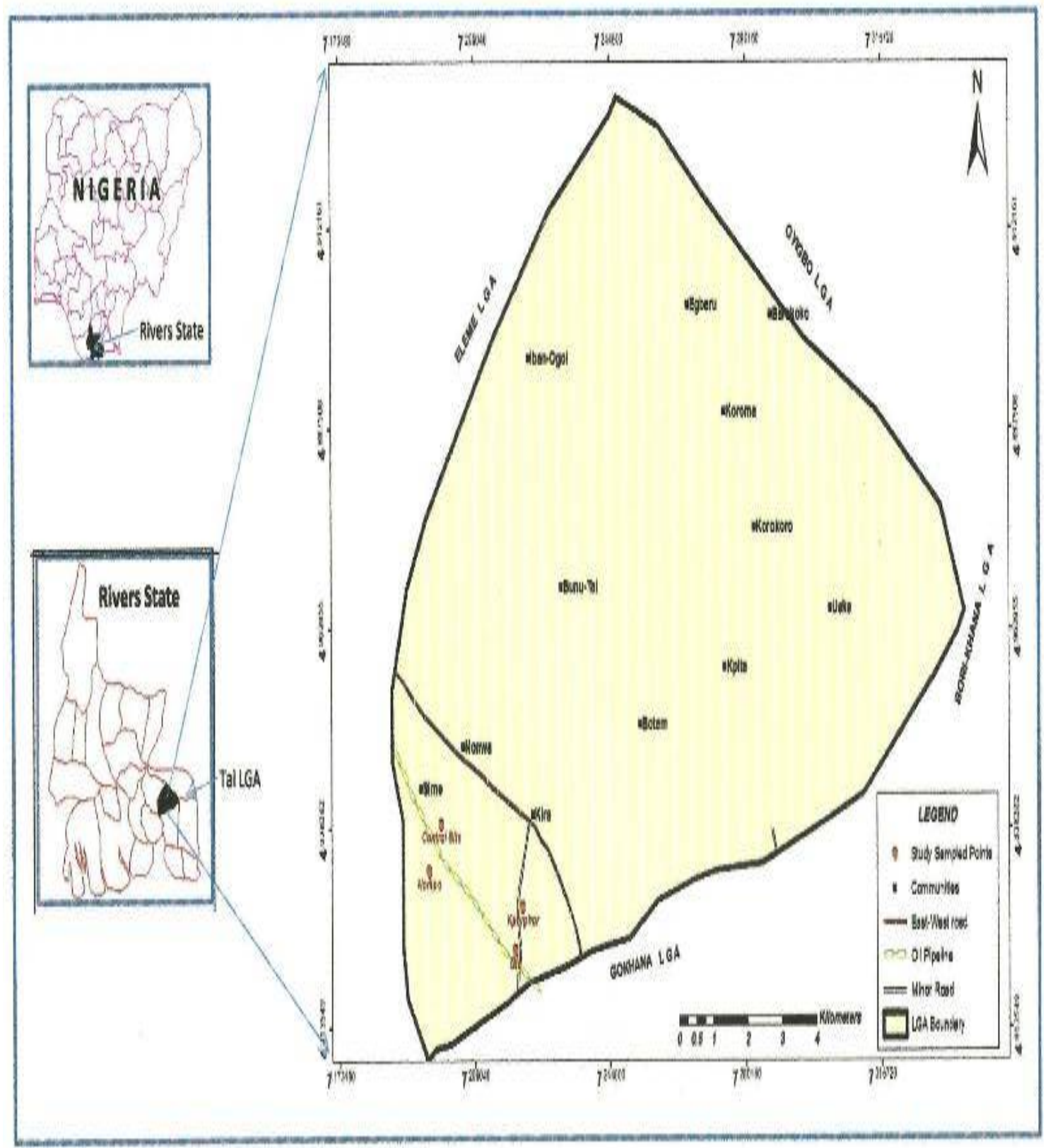

Figure 1. Study Area 


\section{Results}

Approximately $80 \%$ of all mites and $90 \%$ of collembolans were collected within the range, $0.00-10.0 \mathrm{~cm}$ in the unpolluted habitat (Table 1). Similar patterns were observed among the Cryptomastigota and Mesostigmata; but in the Prostigmata, there was a significant positive correlation between soil depth and Prostigmata $(\mathrm{r}=0.937 ; \mathrm{F}=21.54$; $\mathrm{df}=1$, 3 ; $\mathrm{P}<0.05)$. No Prostigmata were collected at depths above $7.5 \mathrm{~cm}$. In contrast, in the habitat, polluted $1 \mathrm{yr}$ pre-study, no mites were collected above $5.0 \mathrm{~cm}$; there were significant positive correlations between soil depth and densities of total mites $(\mathrm{r}=0.952 ; \mathrm{F}=29.11 ; \mathrm{df}=1,3 ; \mathrm{P}<0.05)$ (Figure 2), Cryptostigmata $(\mathrm{r}=0.906 ; \mathrm{F}=13.80 ; \mathrm{df}=1,3 ; \mathrm{P}<0.05)$ (Figure 3), Mesostigmata $(\mathrm{r}=0.936 ; \mathrm{F}=21.12 ; \mathrm{df}=1,3 ; \mathrm{P}<0.05)$ (Figure 4), and Prostigmata $(\mathrm{r}=0.877 ; \mathrm{F}=10.2 ; \mathrm{df}=1,3$; $\mathrm{P}<0.05$ ) (Figure 5) (Table 2). Approximately $70 \%$ of all mites in the habitat polluted (1yr pre-study), were collected below $10.00 \mathrm{~cm}$ (Table 2).

In the habitat polluted 3yrs pre-study, there was an inverse relationship between soil depth and total mite abundance but the correlation between soil depth and density was not significant $(\mathrm{F}=0.21, \mathrm{df}=1,3 ; \mathrm{P}>0.05)$; similar patterns were observed in Cryptostigmata, Mesostigmata, Prostigmata. Approximately $70 \%$ of all mites in this habitat were col- lected above $10.0 \mathrm{~cm}$ (Table 3 ). In the habitat, polluted 6yrs pre-study, there was an inverse relationship between total mite numbers and depth, but the correlation between soil depth and mite densities was not significant $(\mathrm{F}=1.47, \mathrm{df}=1,3$ $\mathrm{P}>0.05$ ); similar patterns were observed between soil depth and Cryptostigmata, Mesostigmata and Prostigmata densities (Table 4). In the unpolluted habitat, approximately $90 \%$ of all collembolans were collected above $10.0 \mathrm{~cm}$ while only $30 \%$ of collembolans in the polluted (1yr pre-study) were collected in this range.

There was an increase to $50 \%$ of collembolans above $10.0 \mathrm{~cm}$ in the polluted (3yrs pre-study) and $85 \%$ in the polluted habitat (6yrs pre-study). There were inverse relationships between soil depths and collembolan abundance in the unpolluted habitat and habitat, polluted 6yrs pre-study but the respective correlations were not significant $(\mathrm{F}=3.2 ; \mathrm{df}=1$, $3 ; \mathrm{P}>0.05 ; \mathrm{F}=3.86, \mathrm{df}=1,3 ; \mathrm{P}>0.05)$. In the habitats polluted $1 \mathrm{yr}$ and $3 y r$ pre-study, there were direct relationships between soil depths and collembolan densities but the correlations were not significant $(\mathrm{F}=6.22 . \mathrm{df}=1,3 ; \mathrm{P}>0.05)$.

Analyses of total Hydrocarbon content of soil from the four habitats: unpolluted, polluted 6yrs, 3yrs and $1 \mathrm{yr}$ pre-study, showed concentrations of 10.0, 12.5, 237.5 and $680.0 \mathrm{mg} / \mathrm{kg}$ respectively.

Table 1. Relationship of Soil depth to Abundance/Density of Mites in an Unpolluted Secondary Rainforest

\begin{tabular}{|c|c|c|c|c|c|c|c|c|}
\hline \multirow{3}{*}{$\begin{array}{l}\text { Depth } \\
(\mathrm{cm})\end{array}$} & \multicolumn{6}{|c|}{ Mites } & \multicolumn{2}{|c|}{ Total } \\
\hline & \multicolumn{2}{|c|}{ Cryptostimata } & \multicolumn{2}{|c|}{ Mesostigmata } & \multicolumn{2}{|c|}{ Prostigmata } & \multirow[b]{2}{*}{ Abundance } & \multirow[b]{2}{*}{ Density } \\
\hline & Abundance & Density & Abundance & Density & Abundance & Density & & \\
\hline $0-5.0^{*}$ & 203 & 7.16 & 901 & 3.18 & - & - & 2932 & 10.34 \\
\hline $5.1-7.5 \#$ & 1835 & 13.48 & 715 & 5.25 & - & - & 2550 & 18.73 \\
\hline 7.6-10.0\# & 1278 & 9.39 & 565 & 4.15 & 95 & 0.70 & 1938 & 14.24 \\
\hline $10.1-12.5 \#$ & 966 & 7.10 & 281 & 2.06 & 87 & 0.64 & 1334 & 9.80 \\
\hline $12.6-15.0 \#$ & 391 & 2.88 & 62 & 0.46 & 150 & 1.10 & 603 & 4.40 \\
\hline
\end{tabular}

Table 2. Relationship of Soil depth to Abundance/Density of Mites in a Secondary Rainforest (Polluted, 1yr pre-study)

\begin{tabular}{ccccccccc}
\hline \multirow{2}{*}{ Depth $(\mathrm{cm})$} & \multicolumn{9}{c}{ Mites } & & \multicolumn{2}{c}{ Total } \\
\cline { 2 - 5 } & \multicolumn{2}{c}{ Cryptostimata } & \multicolumn{2}{c}{ Mesostigmata } & \multicolumn{2}{c}{ Prostigmata } & & \\
& Abundance & Density & Abundance & Density & Abundance & Density & Abundance & Density \\
$0-5.0^{*}$ & - & - & - & - & - & - & - & - \\
$5.1-7.5 \#$ & 32 & 0.24 & - & - & - & - & 32 & 0.24 \\
$7.6-10.0 \#$ & 182 & 1.34 & 65 & 0.48 & - & - & 247 & 1.82 \\
$10.1-12.5 \#$ & 187 & 1.37 & 102 & 0.75 & 20 & 0.15 & 309 & 2.27 \\
$12.6-15.0 \#$ & 194 & 1.43 & 99 & 0.73 & 45 & 0.33 & 338 & 2.49 \\
\hline
\end{tabular}

$*$ : soil volume $=283.58 \mathrm{~cm}^{3}$

$\#$ : soil volume $=136.12 \mathrm{~cm}^{3}$

-: no record

Density $\left(\mathrm{mite} / \mathrm{cm}^{3}\right)$ 
Table 3. Relationship of Soil depth to Abundance/Density of Mites in a Secondary Rainforest (Polluted, 3yrs pre-study)

\begin{tabular}{|c|c|c|c|c|c|c|c|c|}
\hline \multirow[t]{3}{*}{ Depth $(\mathrm{cm})$} & \multicolumn{6}{|c|}{ Mites } & \multicolumn{2}{|c|}{ Total } \\
\hline & \multicolumn{2}{|c|}{ Cryptostimata } & \multicolumn{2}{|c|}{ Mesostigmata } & \multicolumn{2}{|c|}{ Prostigmata } & \multirow[b]{2}{*}{ Abundance } & \multirow[b]{2}{*}{ Density } \\
\hline & Abundance & Density & Abundance & Density & Abundance & Density & & \\
\hline $0-5.0^{*}$ & 420 & $1.48^{-3}$ & 207 & $0.73^{-3}$ & - & - & 627 & $2.21^{-3}$ \\
\hline $5.1-7.5 \#$ & 382 & $2.81^{-3}$ & 155 & $1.14^{-3}$ & - & - & 537 & $3.95^{-3}$ \\
\hline 7.6-10.0\# & 310 & $2.28^{-3}$ & 137 & $1.01^{-3}$ & - & - & 447 & $3.29^{-3}$ \\
\hline $10.1-12.5 \#$ & 293 & $2.15^{-3}$ & 130 & $0.96^{-3}$ & 40 & $0.29^{-3}$ & 463 & $3.30^{-3}$ \\
\hline $12.6-15.0 \#$ & 141 & $1.04^{-3}$ & 91 & $0.67^{-3}$ & 29 & 0.21 & 261 & $1.92^{-3}$ \\
\hline
\end{tabular}

$*$ : soil volume $=283.58 \mathrm{~cm}^{3}$

$\#$ : soil volume $=136.12 \mathrm{~cm}^{3}$

-: no record

Density $\left(\mathrm{mite} / \mathrm{cm}^{3}\right)$

Table 4. Relationship of Soil depth to Abundance/Density of Mites in a Secondary Rainforest (Polluted, 6yrs pre-study)

\begin{tabular}{|c|c|c|c|c|c|c|c|c|}
\hline \multirow[t]{3}{*}{ Depth (cm) } & \multicolumn{6}{|c|}{ Mites } & \multicolumn{2}{|c|}{ Total } \\
\hline & \multicolumn{2}{|c|}{ Cryptostimata } & \multicolumn{2}{|c|}{ Mesostigmata } & \multicolumn{2}{|c|}{ Prostigmata } & & \\
\hline & $\begin{array}{l}\text { Abun- } \\
\text { dance }\end{array}$ & Density & Abundance & Density & Abundance & Density & Abundance & Density \\
\hline $0-5.0$ * & 949 & $3.35^{-3}$ & 419 & $1.48^{-3}$ & - & - & 1368 & $4.83^{-3}$ \\
\hline $5.1-7.5 \#^{*}$ & 859 & $6.31^{-3}$ & 288 & $2.16^{-3}$ & - & - & 1147 & $8.49^{-3}$ \\
\hline $7.6-10.0 \#^{*}$ & 742 & $5.45^{-3}$ & 173 & $1.27^{-3}$ & 45 & $0.33^{-3}$ & 960 & $7.05^{-3}$ \\
\hline $10.1-12.5 \#^{*}$ & 581 & $4.27^{-3}$ & 130 & $0.96^{-3}$ & 31 & $0.23^{-3}$ & 742 & $5.46^{-3}$ \\
\hline $12.6-15.0 \# *$ & 198 & $1.46^{-3}$ & 39 & $0.29^{-3}$ & 60 & $0.44^{-3}$ & 297 & $2.19^{-3}$ \\
\hline
\end{tabular}

$*$ : soil volume $=283.58 \mathrm{~cm}^{3}$

$\#^{*}:$ soil volume $=136.12 \mathrm{~cm}^{3}$

-: no record

Density $\left(\mathrm{mite} / \mathrm{cm}^{3}\right)$

Table 5. Relationship of Soil depth to Abundance/Density of Collembolans in various habitat-types in a Secondary Rainforest

\begin{tabular}{|c|c|c|c|c|c|c|c|c|}
\hline \multirow{4}{*}{$\begin{array}{l}\text { Depth } \\
(\mathrm{cm})\end{array}$} & \multicolumn{8}{|c|}{ COLLEMBOLANS } \\
\hline & \multicolumn{2}{|c|}{ Unpolluted Control } & \multicolumn{6}{|c|}{ Polluted } \\
\hline & \multirow[b]{2}{*}{ Abundance } & \multirow[b]{2}{*}{ Density } & \multicolumn{2}{|c|}{ 1yr pre-study } & \multicolumn{2}{|c|}{$3 y r s$ pre-study } & \multicolumn{2}{|c|}{$\geq 6$ yrs pre-study } \\
\hline & & & Abundance & Density & Abundance & Density & Abundance & Density \\
\hline $0-5.0^{*}$ & 376 & $1.31^{-3}$ & - & - & 97 & $0.34^{-3}$ & 238 & $0.84^{-3}$ \\
\hline $5.1-7.5 \#$ & 323 & $2.37^{-3}$ & - & - & 58 & $0.43^{-3}$ & 209 & $1.54^{-3}$ \\
\hline 7.6-10.0\# & 249 & $1.78^{-3}$ & 56 & $0.41^{-3}$ & 62 & $0.46^{-3}$ & 137 & $1.01^{-3}$ \\
\hline $10.1-12.5 \#$ & 118 & $0.87^{-3}$ & 81 & $0.60^{-3}$ & 120 & $0.88^{-3}$ & 78 & $0.57^{-3}$ \\
\hline $12.6-15.0 \#$ & - & - & 54 & $0.40^{-3}$ & 90 & $0.66^{-3}$ & 13 & $0.10^{-3}$ \\
\hline
\end{tabular}

$*$ : soil volume $=283,58 \mathrm{~cm}^{3}$

\#: soil volume $=136.12 \mathrm{~cm}^{3}$

-: no record

Density (collembolan $\left./ \mathrm{cm}^{3}\right)$

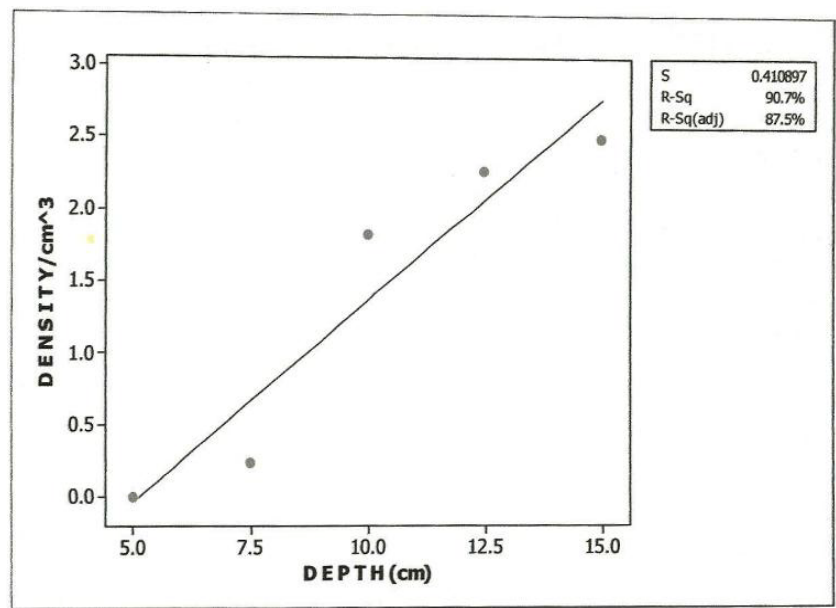

Figure 2. Relationship of total mite density to soil depth in habitat, polluted $1 \mathrm{yr}$ pre-study

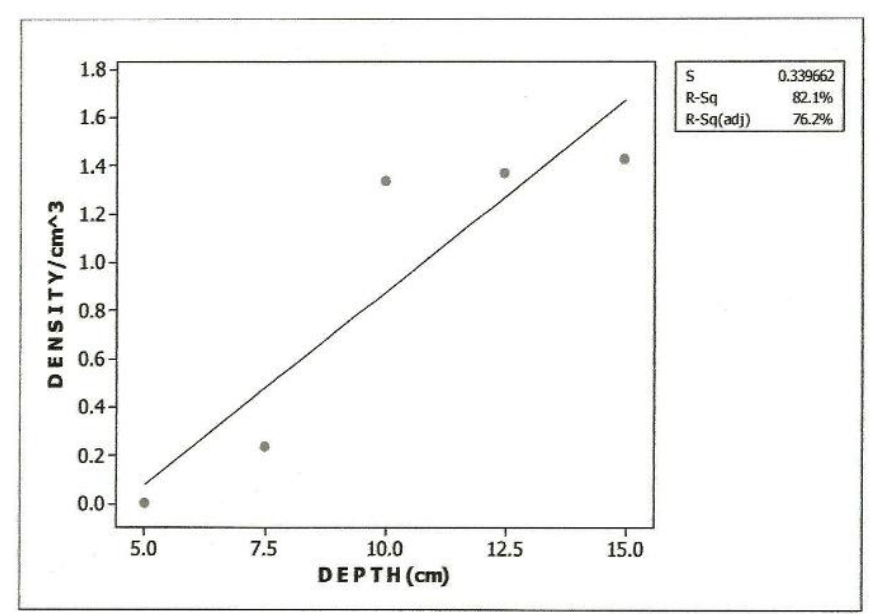

Figure 3. Relationship between Cryptostigmata densities and soil depth in habitat polluted $1 \mathrm{yr}$ pre-study 


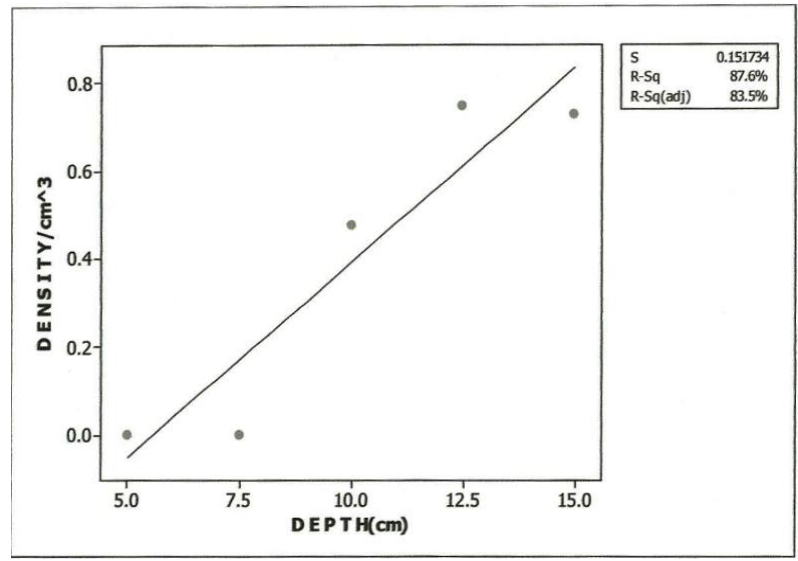

Figure 4. Relationship between Mesostigmata densities and Soil Depth in Habitat, Polluted 1 yr pre-study

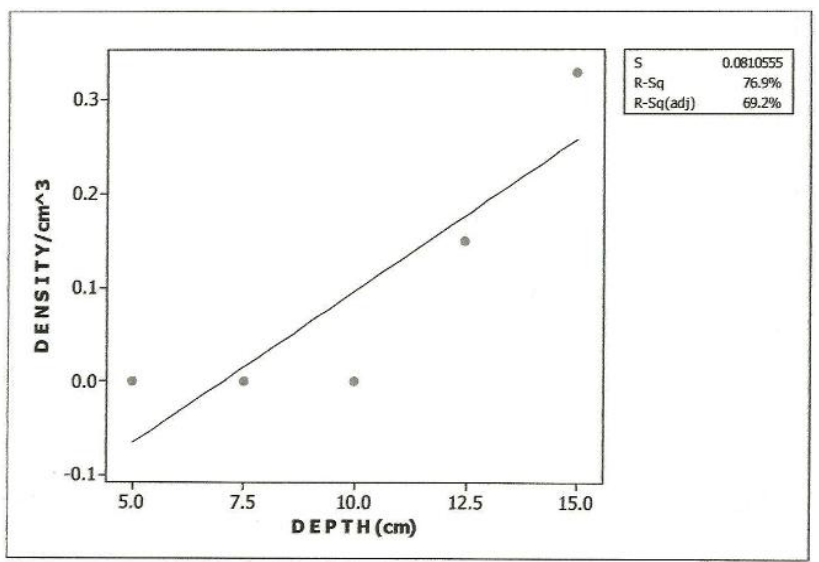

Figure 5. Relationship between Prostigmata Densities and Soil Depth in Habitat, Polluted 1yr Pre-study

\section{Discussion}

In the unpolluted habitat, $80 \%$ of all mites and nearly $80 \%$ of all Collembolans were found at depths above $10.0 \mathrm{~cm}$. In contrast, the effect of the oil spill in the polluted habitat $(1 \mathrm{yr}$ pre-study) was the reduction of mites in this zone to $30 \%$; there was also a significant reduction in overall mite numbers. It was apparent that the effects of the oil spill were more pronounced in the uppermost layers, $0-10.0 \mathrm{~cm}$. These effects were probably direct (lethal concentrations) and/ or indirect (adversely affecting food sources, microarthropod reproductive rate or soil quality). Seniczak et al. classified Oribatids into 3 categories (quite susceptible, less susceptible, and tolerant) based on their reaction to heavy metals[2] . These categories may also be applicable to their responses to the oil spill. The low- dispersing, near sedentary, low metabolic Oribatids, the mainly predaceous Gamasid (Mesostigmata) and the Prostigmata were all adversely affected in the $0.0-10.0 \mathrm{~cm}$ range. The low numbers found below $10.0 \mathrm{~cm}$ were probably species in Seniczak et al. tolerant category[2].

It is apparent that Prostigmata, by predominantly inhabiting depths below $10.0 \mathrm{~cm}$ may have adopted this strategy for the avoidance of unfavourable conditions[6]. Percents of mites and collembolan species that re-colonized the top $10.0 \mathrm{~cm}$ of soil rose from $70 \%$ (mites) and $50 \%$ (collembolans) in the habitat polluted 3yrs pre-study to $75 \%$ (mites) and $85 \%$ (Collembolans) in the habitat polluted 6yrs pre-study. Although re-colonization of the top $10.0 \mathrm{cmof}$ soil based on species richness was noticeable in the habitat polluted $3 y$ rs pre-study, there was no corresponding increase in abundance/density. Abundance/density in the most recently polluted (1yr pre-study) habitat was about $10.0 \%$ of that in the unpolluted habitat, $25 \%$ in the habitat polluted $3 \mathrm{yrs}$ pre-study and $50 \%$ in the habitat polluted (6yrs pre-study). The re-colonization (based on abundance/density) was more rapid in collembolans: $17.91 \%$ (1yr pre-study), $40.05 \%$ (3yrs pre-study) and $63.32 \%$ (6yrs pre-study)[24]. This is not surprising because the Oribatids, the dominant mite order, have characteristics that render them unable to respond quickly to short-term hard stresses[25].

\section{Conclusions}

In the unpolluted habitat, most of the mites (Cryptostigmata, Mesostigmata) and Collembolans were found in the top $10.0 \mathrm{~cm}$-soil where they play a key role in decomposition and mineralization processes. The oil spill reduced abundance and caused movement of the mesofauna to lower layers, particularly in the habitat polluted $1 \mathrm{yr}$ pre-study. Re-colonization of the top $10.0 \mathrm{~cm}$-soil occurred in habitats polluted 3yrs and 6yrs pre-study. The Prostigmata occupied lower layers, below $7.5 \mathrm{~cm}$ in the unpolluted and polluted habitats.

\section{REFERENCES}

[1] Minor M.A., Volk T. A., Norton R.A. 2004. Effects of site preparation techniques on communities of soil mites (Acari: Oribatidad, Acari:Gamasida) under short rotation forestry plantings in New York, USA. Applied Soil Ecology 25:181-192

[2] Seniczak, S., Dabrowski, J., Dlugosz, J. 1995. Effect Of Copper Smelting Air Pollution On The Mites (Acari) Associated With Young Scots Pine Forests Polluted By A CopperSmelting Works At Giogow, Poland. I. Arboreal Mites. Water, Air, and Soil Pollution. 94(3-4): 71-84

[3] Zaitsev A.S., Van Straalen N.M. 2001. Species diversity and metal accumulation in oribatid mites (Acari, Oribatida) of forests affected by a metallurgical plant. Pedobiologia. 45(5): 467-479

[4] Skubala, P., Kafel, A. 2004. Oribatid mite communities and metal bioaccumulation in oribatid species (Acari, Oribatida) along the heavy metal gradient in forest ecosystems. Environmental Pollution. 132(1): 51-60

[5] Migliorini, M., Pigino, G., Caruso, T., Fanciulli, P.P., Leonzio, C., Bernini, F. 2005. Soil communities (Acari Oribatida, Hexapoda: Collembola) in a clay pigeon- shooting range. Pedobiologia 49(1): 1-13 
[6] Bedano, J.C., Cantu, M.P., Doucet, M.E. 2005. Abundance of soil mites (Arachnida:Acari) in a natural soil of central Argentina. Zoological Studies. 44(4):505-512

[7] Salmon S., Mantel J., Frizzera I., Zanella A. 2006. Changes in humus forms and soil animal communities in two developmental phases of Norway spruce on an acidic substrate. Forest Ecology and Management.237:47-56

[8] Mitchell R.J., Campbell C.D., Chapman S.J., Osler G.H.R., Vanbergen A.J., Ross L.C., Cameron C.M., Cole L. 2007. The cascading effect of birch on heather moorland: a test for the top-down control of ecosystem engineer. Journal of Ecology. 95:540-554

[9] Andre H.M., Noti M. I., Lebrun P. 1994. The soil fauna- The other last biotic frontier. Biodiversity and Conservation. 3:45-56

[10] Cole L., Bucklands S.M., Bardgett R.G. 2008. Influence of disturbance and nitrogen addition on plant and soil animal diversity in grassland. Soil Biology \& Biochemistry. 40:505-514

[11] Liiri M. Haimi J., Setala H. 2002. Community composition of soil microarthropods of acid forest soils as affected by wood ash application. Pedobiologia. 46:108-124

[12] Fox C.A., Fonseca E.J.A., Miller J.J., Tomlin A.D. 1999. The influence of row position and selected soil attributes on Acarina and Collembola in no-till and conventional continuous corn on a clay loam soil. Applied Soil Ecology

[13] Badejo, M.A., Woas, S., Beck, L. 2001a. Mesoplophora ifeana, a new species of ptychoid mite (Acari, Oribatida) from Nigeria. Andrias. 15:65-73

[14] Badejo, M.A., Woas, S., Beck, L. 2001b. Description of Astropacarus (Hoplophorella) nigeriensis, a new species of phthiracarid mites from Nigeria. Andrias. 15:55-63

[15] Badejo, M.A., Woas, S., Beck, L. 2002a. New pterogasterine mites from Nigeria and Brazil Sceloribates, Muliercula and Peloribates. Systematic and Applied Acarology. Special
Publication. 12, 1-60

[16] Badejo, M.A., Woas, S., Beck, L. 2002b. Description of six species of natroid mites from Nigeria and Brazil (Acari: Oribatida: Northroidea). Genus 13(4): 505-548

[17] Gbarakoro T. N., Okiwelu S. N., Badejo M. A., Umeozor O. C. 2010. Soil Microarthropods in a Secondary Rainforest in Rivers State, Nigeria. -I- Seasonal Variations in species Richness, Vertical Distribution and Density in an Undisturbed_Habitat. Scientia Africana 9(1): 48-56

[18] Okiwelu S.N., Gbarakoro T.N. and Badejo M.A. 2011. Soil Microarthropods in a secondary Rainforest, Rivers State, Nigeria. Journal of ecology and Natural Environment 3(1):29-32

[19] Lasebikan B.A. 1974. Preliminary Communications on Microarthropods from a tropical rainforest in Nigeria. Pedobiologia 14:402-411

[20] Badejo, M.A. 1996. Measuring the diversity of soil microflora and microfauna in an area of conservation of biodiversity. In Biosphere resources for diversity conservation and sustainable development in Anglophone Africa (BRAAF), assessment and monitoring techniques in Nigeria, Abeokuta, Nigeria

[21] Krantz, G.W. 1978. A Manual of Acarology. Oregon 173 State University Book Stores Inc. Corvallis

[22] Norton, R.A. 1990. Acarina: Oribatida. In Dindal, D.L.(Ed.) Soil Biology Guide. John Wiley, New York, pp 779-803

[23] Woolley T. A. 1990. Acarology: mites and human welfare. New York. John Willey. 463pp

[24] Hopkins S.P. 1997. Biology of the springtails (Insecta: Collembola). Oxford University Press, Oxford

[25] Behan-Pelletier, V.M. 1999. Oribatid mite biodiversity in agro- ecosystems and environment: role for bioindication. Agriculture, Ecosystems and Environment. 74: 411-423 